\title{
Technical Efficiency of Red Pepper Production and Its Determinants Among Smallholder Farmers in Shashogo District of Hadiya Zone, SNNP Region, Ethiopia
}

\author{
Berhanu Getinet Kibret(Asst. Professor) \\ Corresponding Author \\ Department Of Economics, College Of Business And Economics, Hawassa University, Ethiopia \\ Mathewos Teshale Abebo(MA) \\ Co-author \\ Finance and Economic Development office, Hadiya zone \\ Southern Nations, Nationalities And Regions People, Ethiopia
}

\begin{abstract}
This study briefly estimates the technical efficiency level of red pepper production and identifies its determinants that influence the technical efficiency. To analyze data, both descriptive statistics and econometric models were used. Stochastic Frontier function that incorporated inefficiency factors was to provide estimates of technical efficiency and its determinants using data obtained from 119 randomly selected sample red pepper producers from three kebeles of the study district. The Trans log production function was found to adequately fit the data. The maximum likelihood parameter estimates showed that almost all input variables have positive and significant effects on production except land size which is allocated for red pepper production. The analysis showed that the mean technical efficiency of farmers was $73.66 \%$, implying that output in the study area can be increased by $26.34 \%$ at the existing level of inputs and current technology by improving determinants of technical efficiency. Technical inefficiency effects are modeled as a function of farmer specific socio-economic factors. The result showed that among the variables that are supposed to determine technical inefficiency, education level of farmers, age, distance from residence to plot, experience, credit access, extension visit, slope of land and proximity to market are significantly influencing technical inefficiency of red pepper producers. Moreover, education, distance, extension visit, proximity to market and credit access tends to increase technical efficiency of farmers whereas age of household, poor quality of soil and slope of land decrease their technical efficiency. Therefore, the road, net work in the rural areas; development of telecommunication facilities, rural market centers (institutions) should have to be advocated and promoted by farmers and government to overturn output loss by technical inefficiency of red pepper producers in Shashogo District.
\end{abstract}

Keywords: Technical efficiency, stochastic frontier, determinants, red pepper, Shashogo District

DOI: $10.7176 / \mathrm{JRDM} / 58-04$

Publication date: August $31^{\text {st }} 2019$

\section{INTRODUCTION}

Though agriculture remains to be the most important sector of the Ethiopian economy, its performance has been disappointing and food production has been lagging behind population growth (Demeke, 2008) and unable to fulfill the requirement of the ever-increasing demand of foods. Poor use of modern inputs can partly explain the low productivity of the sector and the inefficiency of the farmers in using the available agricultural resources (Kindie, 2005). Despite substantial attempt on part of government to commence technological improvement in agriculture, the productivity of the agricultural sector is so low and remains a challenge.

Red Pepper is one of the most varied and widely used food items in the world. It is a prominent cash crop for many developing countries farmers such as Ethiopia, Nigeria, Ghana, China, India, Pakistan, Bhutan, Indonesia, Cambodia and Thailand (Shih-wen et al., 2013). According to (CSA, 2016) from the total estimated area under vegetables production in Ethiopia, the lion share which accounts about $70.93 \%$ has been under red pepper. The production of red pepper could be said to have remained in the hands of small-holder rural farmers. But rural farmers in Ethiopia are resource poor and operate on small-scale. They hardly use mechanized and other improved agricultural inputs and so it can be asserted that they still carry out their agricultural activities i n the 'traditional ways' and therefore remains inefficient (Almaz et al., 2014). The productivity of red pepper production in the country is low due to various constraints that include traditional method of production, usage retained seed, disease and absence of pesticide to control pests, shortage of improved varieties, lack of proper and adequate inputs, delay in supply of input and lack of research and technological progress(Solomon et al., 2012). Thus, intensification of production would be necessary for increasing productivity on declining farm sizes. The sector can be a viable enterprise for income generation, poverty alleviation, job creation and improvement of food security to every household if the production is efficiently made(Mohammed et al., 2015). 
Therefore, this research investigated technical efficiency of red pepper production and its determinants among smallholder farmers in Shashogo District, southern Ethiopia .

\section{STATEMENT OF THE PROBLEM}

Economists argue that the achievement of (greater) efficiency from scarce resources should be a major criterion for priority setting especially in developing agriculture led economies. To them, farmers can still produce maximum possible output from fixed set of inputs under the present technology. The efficiency with which farmers use available resources and improved technology is important in agricultural production. This implies that increased efficiency is associated with the quality of resources used, quantity and increased mobilization and efficient utilization of resources.

The red pepper is one of the most important food items and cash crop in Ethiopia, it is unquestionable to improve its productivity. In order to achieve self sufficiency in pepper production, there is an urgent need to assess and understand the efficiency of production in pepper farming and different factors contributing to the inefficiency in advance helps to improve efficiency with a view to bring a desired change in the sector. Studies so far conducted on the productivity and efficiency of agricultural production in Ethiopia have not given much emphasis for pepper efficiency despite its important role as livelihood of the people. Of course, some researchers found technical efficiency improvement as a solution for the productivity problem through better information, credit provision, market access, extension service and education( Alemu et al.,2009; Tsegaye et al.,2004;Weir and Knight,2004; Tassew et al.,2004; Jema, 2008).

The number of studies are limited and far from exhaustive which in turn results in paucity of literature in the sector. In addition, the existing studies show a narrow focus in terms of study methodologies such as sampling procedure and variables considered for efficiency analysis (Tewodros, 2001). To bridge this gap, it would be necessary to conduct research on the efficiency issues to design and formulate policies and strategies for the sector development. Therefore, this paper investigated the efficiency of red pepper farmers and its determinants that aimed at increasing production and improving efficiency of the study area and the country large.

\section{RESEARCH QUESTIONS}

Therefore, this study seeks to provide answers to the following research questions:

- What is the technical efficiency level of red pepper farmers in the Shashogo District?

- What are the factors affecting the technical efficiency of red pepper producers in the study area?

\section{OBJECTIVES OF THE STUDY}

Besides, the study addressed the following specific objectives:

- To estimate the level of technical efficiency of red pepper producers in Shashogo District; and

- To identify determinants technical efficiencies of red pepper producers in the study area

\section{THE SIGNIFICANCE OF THE STUDY}

This study indicates an entry point for policy interventions to improve the efficiency of red pepper smallholder farmers as it come up with important idea of efficient utilization of available production inputs. The study will also be the baseline and contribute to literature on red pepper production for the area and the neighboring districts and other potential producers at large . Moreover, it has a substantial contribution in assisting policy makers as well as development workers to focus on the efficiency level and those efficiency determinants identified in order to improve farm efficiency and in turn improve productivity and income of the farmers in the study area.

\section{METHODOLOGY OF THE STUDY}

\section{Research Design}

This study employed a cross- sectional survey design to explain the situation with a holistic assessment of both quantitative and qualitative data obtained from a questionnaire and interview

\section{Data Type and Sources}

To attain the stated objectives, the researcher collected primary data on the technical coefficients (inputs-outputs) of red pepper production and socioeconomic characteristics of farmers using structured questionnaire. Qualitative data was also collected from key informant interviews. The secondary data was collected from published and unpublished documents such as reports.

\section{Sampling Procedure and sample size determination}

A multistage sampling procedure was employed to select the sample. At first stage, the study area is selected purposively for the high production of red pepper. In the second stage, the pepper producing 26 kebeles were stratified into lowland and mid altitude agro-ecologies based on stratified sampling. At the third stage, three potential pepper producing kebeles are randomly selected ( 2 kebeles from 16 lowland and 1 kebele from 10 mid altitude) based on production coverage of red pepper. From these selected kebeles, total of 3,460 households 
produce red pepper. Finally, based on the sampling frame from each kebele, random sampling technique was used to select the sample households.

This study adopts the sample size determination formula of Yamane (1967) as:

$$
\begin{gathered}
n=\frac{N}{1+N(e) 2} \\
n=\frac{3,460}{1+3,460(0.09) 2}=119 ; .
\end{gathered}
$$

Where: $\mathrm{n}=119$ was the total sample size planned to be covered, $\mathrm{N}=3,460$ is the population size (total population of red pepper producers in the selected three kebeles), and $\mathrm{e}= \pm 9 \%$ is the level of precision where confidence level is $91 \%$.

The selected sample sizes was determined from three kebeles by proportionate random sampling technique. The kebeles considered for the study were Kemecho-Borara, Alagie \& Jemaya.

Methods of Data Analysis

The study has made both descriptive and econometric analysis. Regarding econometric aspect, the technical efficiency and their determinants were estimated using a one step maximum likelihood estimate (MLE) procedure. Basically, the choice of functional form is of prime importance in the stochastic production frontier estimation. Consequently, Trans log functional form is supposed to fit the data under the study adequately.

\section{Model specification}

This study is based on stochastic frontier model( Aigner et al 1977). In this model, both the stochastic and the technical inefficiency effects in terms of observable variables, and estimating all parameters by the method of maximum likelihood in a one - step analysis was employed. This was used for estimation of the stochastic frontier model in conjunction with the parameters of the variables included to explain efficiency effects, as developed by Coelli and Berret( 1995).

A range of functional forms for the production function frontier are available, with the most frequently used being a Trans log function, which is a second order (all cross-terms included) log-linear form. As broadly described in Kumbhakar and Lovell (2005), the Trans log function is an attractive flexible function. Moreover, this is a relatively flexible, as it does neither impose assumptions about constant elasticity of production nor elasticity of substitution between inputs. Accordingly, Trans log functional form was used in this study to show the interaction effects of factor inputs in the red pepper production.

\section{Model A: Production function}

The Cobb-Douglas Stochastic Frontier Production Function was specified in order to estimate the level of technical efficiency and its functional form is as follows:

$\mathrm{Y}=\beta 0 \quad \mathrm{X} 1^{\beta_{1}} \quad \mathrm{X}^{\beta_{2}} \quad \ldots \ldots \ldots . .6^{\beta_{6}} \mathrm{e}^{\mathrm{V}_{\mathrm{i}-\mathrm{U}_{\mathrm{i}}}}$

The above function is linearized double-log form:

$\ln \mathrm{Y}=\ln \beta 0+\beta 1 \ln \mathrm{X} 1+\beta 2 \ln \mathrm{X} 2+\beta 3 \ln \mathrm{X} 3+\beta 4 \ln \mathrm{X} 4+\mathrm{Vi}-\mathrm{Ui}$

whereY = Output (kg/ha); X1 = Human labor (man days/ha) ; X2 = Farm size (ha) ;X3 = Fertilizer $(\mathrm{kg}) ; \mathrm{X} 4=$ Capital (birr)

The model of the technical inefficiency effects in the stochastic production frontier equation is defined by: $\mathrm{U}_{\mathrm{i}}=\delta_{0}+\delta_{1} \mathrm{Z}_{1}+\delta_{2} \mathrm{Z}_{2}+\delta_{3} \mathrm{Z}_{3}+\delta_{4} \mathrm{Z}_{4}+\ldots .+\delta_{14} \mathrm{Z}_{14}+\mathrm{w}_{\mathrm{i}}$

Where, $X_{1}, X_{2}, X_{3}, X_{4}$ and $Z_{1}, Z_{2} \ldots Z_{14}$ are explanatory variables.

$\mathrm{U}$ is one-sided technical inefficiency effect under the control of farmer having a positive half normal distribution $\left\{\mathrm{U}_{\mathrm{i}} \sim\left|\mathrm{N}\left(0, \sigma_{\mathrm{u}}^{2}\right)\right|\right\}$ and $\mathrm{W}_{\mathrm{i}}$ is two-sided uniform random variable and is unobservable random variable having a positive half normal distribution. The model was estimated simultaneously using Frontier Package 4.1.

The $\beta$ and $\delta$ coefficients are unknown parameters to be estimated together with the variance parameters which are expressed in terms of $\sigma^{2}=\sigma_{\mathrm{u}}{ }^{2}+\sigma_{\mathrm{v}}{ }^{2}$ and $\gamma=\sigma_{\mathrm{u}} / \sigma_{\mathrm{v}}$; Where, $\gamma$ parameter has value between zero and one.

\section{Model B : Determinants of Technical efficiency}

In this section, the distribution of $u \mathrm{i}=\mathrm{E}$ (ui/ei) is derived and discussed from stochastic frontier model with the help of one step approach given the assumptions zero mean, unknown variance $\delta v 2$ and non-negative random term, ui ,associated with technical inefficiency of production, which are assumed to be independently distributed, such that ui is obtained by truncation (at zero) of the normal distribution with mean ui (under truncated normal distribution) and variance $\delta \mathrm{u} 2$; where the mean of ui, is defined by the equation of the socioeconomic factor (Coelli, 1995) hypothesized as determinants of TE, can be stated as:

$\mathrm{U}_{\mathrm{i}}=\delta_{0}+\delta_{1} \mathrm{Z}_{1}+\delta_{2} \mathrm{Z}_{2}+\delta_{3} \mathrm{Z}_{3}+\delta_{4} \mathrm{Z}_{4}+\delta_{5} \mathrm{Z}_{5}+\delta_{6} \mathrm{Z}_{6}+\delta_{7} \mathrm{Z}_{7}+\delta_{8} \mathrm{Z}_{8}+\delta_{9} \mathrm{Z}_{9}+\delta_{10} \mathrm{Z}_{10}+\delta_{11} \mathrm{Z}_{11}+\delta_{12} \mathrm{Z}_{12}+\delta_{13} Z_{13}+\delta_{14} Z_{14}+$ $\mathrm{W}_{\mathrm{i}}$

Where:

$\mathbf{U}_{\mathbf{i}}=$ technical inefficiency (the mean of error term under truncated normal distribution), Z's represents socioeconomic factors supposed to be the determinants of technical inefficiency component.

$\mathrm{Z1}=$ Sex of household; Z2= Age of household(Z2; Z3= Family size; Z4=Education; Z5=Experience; Z6=Red 
pepper disease; $Z 7=O f f$ farm income; $Z 8=$ Credit access; $Z 9=$ Distance to plot; $Z 10$ : Extension visit; $Z 11=$ Proximity to market; $Z 12=$ Fertility of soil and $Z 13=$ Slope of land $; \boldsymbol{\sigma}_{\mathbf{i}}=$ parameters to be estimated.

The parameters for the stochastic frontier production function model were obtained by maximum likelihood estimation method using the Frontier 4.1 where equations 3 and 4 were jointly estimated. Here negative and positive signs of the parameters reveal that they can increase and decrease farmer's technical efficiency, respectively. $\mathrm{w}_{\mathrm{i}}=$ unobserved random error term; $\mathrm{i}=$ number of farmers (1-119 sample respondents).

The maximum likelihood estimation (MLE) procedure was used as estimation is more efficient in estimating the coefficients of stochastic production function and also it is possible to estimate the inefficiency effect simultaneously. In addition to STATA 13, FRONTIER 4.1 was used in estimating the maximum likelihood estimators of all the models in this study. This software is a single purpose package' specifically designed for the estimation of stochastic production frontiers (Herrero and Pascoe, 2002). The stochastic frontier and inefficiency models estimation, moreover, is based on the values gamma $(\gamma=\Lambda 2 / 1+\kappa 2)$, lamda $(\Lambda=\delta u / \delta v)$, sigma2u $(\delta u 2)$; $\operatorname{sigma} 2 \mathrm{v}(\delta \mathrm{v} 2)$ and $\operatorname{sigma}(\delta 2=\delta \mathrm{u} 2+\delta \mathrm{v} 2)$ which are simultaneously estimated using Stata 13 . If the variance parameter $\kappa$, which implies total variation in output from the frontier due to technical inefficiency, is statistically significant it clearly reveals the presence of technical inefficiency. Similarly, the value of gamma shows the percentage of total variation caused by technical inefficiency of farmers concerned under the study.

\section{DEFINITION OF VARIABLES AND WORKING HYPOTHESES}

\section{Model A : Production function}

The dependent and independent variables in the stochastic frontier production function of red pepper in the study area as follow:

Dependent variable (output): It is the physical amount of red pepper in quantity that the sample households obtained from their farm during the production season and it is a continuous variable.

Independent variables:

Farm size (FRMSIZE): This refers to the amount of land allocated to red pepper production during study period in hectare (ha). Basically, land positive coefficient is expected.

Labor (LABOR): This input captures family and hired labor is used by the sample households for different agronomic practices of red pepper production measured in man-days. It is converted to man-equivalent using conversion factors for different labor classes participated in the production process as adopted from storck et al., (1991). It is the total labor needed for the maintenance of red pepper production for crop season.

Capital (CAPTL): - The amount of durable goods or stock or any non-financial asset that is used in red pepper production process during the crop season expressed in terms of Ethiopian Birr. It is expected to have positive relation with efficiency

Fertilizer (FRTLZR): The amount of fertilizers (Urea/DAP) used by farmers for their red pepper crop in the production year of 2016/17 measured in $\mathrm{kg}$. Application of fertilizer is expected to increase the level of production and thus influence efficiency positively.

\section{Model B: Determinants of Technical efficiency}

These are variables hypothesized to explain the difference in production efficiency among farmers. These variables are selected based on previous studies and socioeconomic conditions of the study area.

The household head age (HHAGE): This is measured by the age of household head in years. As age of household increases, farmers tends to adapt the environments, get more experienced and challenge the problem they face in the past. The degrees of inefficiency are supposed to declines as age of household increases; negative coefficient is expected with inefficiency.

Education (EDUC): this refers to formal education measured in years of schooling of the farmer will be expected to influence production efficiency positively. Educated farmers are expected to have more exposure to the external environment and accumulated knowledge through formal learning which might enable them to pursue production strategy that leads to better efficiency. Ismat et al. (2009) found evidence that schooling improves technical and economic efficiencies.

Extension contact (EXNCONTACT): This variable is measured as continues variable of frequency of contacts with extension workers in a year. The more frequent contact between farmers and development agents, the more the information flows and the technological (knowledge) transfer from the latter to the former. Extension contact was found to affect economic efficiency positively in the work of Nyagaka et al. (2009).

Family size (FAMSIZE): This variable is measured as a continuous variable by taking the total number of family members in the household. Family size was related to economic efficiency positively in the work of Mbanasor et al. (2008). On the other hand, others argued that increase in family size would increase expenditure for home consumption that can affect the efficiency of farmers negatively by creating financial constraints. Hence, the effect of family size on production efficiency is not determined a priori.

Sex of household head (HHSEX): is a dummy variable that is included to estimate the impact of gender on technical efficiency level of farmers. This is expected to affect production inefficiency either positively or 
negatively.

Credit (CRDT): This is a dummy variable which represents whether the farmer has obtained credit or not during the production year. If the farmer had access to credit, the variable takes a value of one and zero, otherwise. Farmers who got credit would purchase inputs necessary to improve productivity. This variable is expected to have positive effect on efficiency as also found by Nyagaka et al. (2009.

Distance to the plot (PLOTDSTC): This is the distance between the farm where red pepper is cultivated and residence of the respondents measured in $\mathrm{km}$ and it is assumed to have negative impact on efficiency and this is also indicated by Alemayehu (2011). This is because the farmer requires longer time to visit the farm and manage properly and the frequency of the visit will be reduced; thus inefficiency of farmers increases as the distance between farm and homestead increases.

Proximity to nearest market (PROXIMKT): This variable represents the distance between a household residence and the nearest market center measured in $\mathrm{km}$. It is hypothesized that distance from market place is negatively related to efficiency as those farmers far away from market are less accessible for farm inputs, market information and transportation become costly and difficult. It is, therefore, expected that households nearer to market center would have better chance to be efficient than those far away from market centers and even this is supported by Essa (2011). By contrast, other people argue that access to markets may increase the non-farm employment opportunities leading them to reallocate labor from farm to non-farm activities. Hence, the effect of distance to market on production efficiency is indeterminate.

Soil fertility (SOILFRTLTY): This is measured as a dummy variable that takes a value of 1 if a household perceives his farm as fertile and 0, otherwise. This variable is hypothesized to determine efficiency positively as the fertile land is more productive than less fertile once. The same result was found by Fekadu (2004).

Off/non-farm activities (OFFARMACT): This variable is measured as continues variable that took the amount of money the farmer received from engagement in off/non-farm activities. Its effect on efficiency is indeterminate. If farmer spends more time on off/non-farm activities relative to farm activities, this might negatively affect agricultural activities and hence efficiency. The same result was found in the work of Haileselassie (2005). It can also affect efficiency positively by alleviating financial constraints in terms of timely purchase of necessary farm inputs and this is inline with Kindie (2005).

Red pepper production experience (EXPRCE): this is a continuous variable measured in number of years the farmer spent in the production of red pepper. It is hypothesized to have positive effect on farm efficiency as experienced farmers would acquire knowledge and skills that are required for prudent resource allocation and this is a similar result found by Ismat et al. (2009)

Variety of red pepper seed (SEEDVARIETY): Is also captured by binary variable having value of 1 if farmer used high yielding variety which could resist bad environmental conditions (natural or manmade) called improved seed, and 0 , otherwise. The high yielding variety is not only productive. Thus, farmers with improved variety are more productive and efficient than others.

Red pepper diseases (DESEASES): This dummy variable having the value of 1 if there is red pepper disease in the pepper farm (plot) and, 0 otherwise. The prevalence of red pepper disease hurts the level of the production and decreases level of productivity and the degrees of inefficiency increases. The coefficient of this variable is expected to have positive impact on the technical inefficiency of red pepper producers.

Slope of the land (LANDSLOPE): Slope of the land may affect level of production. For instance steep plots are usually subject to water erosion that they are likely to be of lower productivity. To capture the effect of plot topography on efficiency of an index was constructed. The indices for the slope of the land was constructed based on the respondents' response on the slope as their plot is flat, semi-flat and steep.

\section{RESULT AND DISCUSSIONS}

\section{Descriptive Analysis Result}

The study revealed that $93.28 \%$ of the farmers are males and remaining $6.72 \%$ of households are female headed. This shows that active involvement of men in farming activities. The study also indicated that the average age of the respondents were 44.26 years, with 64.4 per cent of the farmers being less than 45 years old the remaining 35.6 percent were above 45 years old. This implies that majority of the farmers are still in their active age and thus expected to be productive, ceteris paribus. The finding further revealed that the mean family size was approximately 7 persons per household. About 85.8 percent of the farmers were educated. The average size of the land allocated for red pepper was 1.60 hectare per household.

In the study area, $75.63 \%$ of the respondent's soil fertility was good while only $4.2 \%$ of the respondents reported their soil type is poor and remaining $20.17 \%$ was medium soil. This made favorable condition for the production and productivity of the red pepper. Similarly, the finding showed that $79.0 \%$ of the respondent's red pepper producing land was flat and $8.4 \%$ and $12.6 \%$ land were steep and medium respectively which in turn can improve the productivity. Red pepper disease is one of important factor that has negative impact on productivity. The survey showed that abou $81.50 \%$ of the respondent confirmed that there was red pepper disease on their 
farm. Moreover, it was expected that farmers to use high yielding variety which could resist bad environmental conditions. However, in the study area, only $10.08 \%$ of the respondents used the improved variety of seed.

The other variable included in the inefficiency model was off farm income earned by household. Off farm income enables farmers to purchase inputs and hence contribute to productivity positively. The average amount was 4,061.78 Birr. Similarly, access to credit is source of financing agricultural activities and it helps farmers to increase productivity. The average amount of credit access was 3,871.93 birr. The mean farming experience was about 13.5 years, with $70.8 \%$ having below 21 years of experience in farming. This implies that the farmers are relatively less experienced. The study also revealed that the average extension visits were around 8 days per month and this is an important incentive in farm production as it aids information dissemination and adoption strategies.

The major inputs used in red pepper production include seed variety, labor, land, capital and fertilizer. It is evident that there was a wide variation in both inputs use and output yields as shown by larger values of standard deviation. Such variation indicates that available resources were not used efficiently. The sample household had an average farm size of 2.47 hectare per household and the average land size allocated for red pepper was 1.60 hectare. The average amount of capital used during last study season was 3,880.14 Birr with standard deviation of 727.09 Birr which shows high variation of capital used by households. Similarly, the average hours of labor used during last red pepper season was 885.02 hours with standard deviation birr 137.08. Another input in red pepper crop is inorganic fertilizer and farmers were using on average 1,358.9 $\mathrm{kg}$ with standard deviation of 540.65. Farmers were using large amount of manure because it was less costly compared with inorganic fertilizer ; and this further enable them to produce more. Moreover, the average productivity of red pepper under study area was $1,452.75 \mathrm{~kg}$ per hectare though the productivity standard would be about 2,200 $\mathrm{kg}$ per hectare, so it was less by $747.25 \mathrm{~kg}$ from standard due to the inefficiency problem.

\section{Model results}

\section{Model A: Estimation of stochastic frontier production}

The maximum likelihood estimation is more efficient in estimating the coefficients of stochastic production function the inefficiency effects in the model simultaneously. Moreover, MLE has many desirable large sample properties and is preferred to other estimators like OLS. In the frontier model, the coefficients of all inputs except capital allocated to production of red pepper were positive and significantly contributing the optimum level of output. Therefore, by increasing these inputs at optimum level, it is possible to improve the technical efficiency of producers.

From the table 1, the most of the variables determining technical inefficiency are also statistically significant. The estimates of lambda $(K)$ is 2.37 (the variance parameter showing the ratio between the normal error term and half normal positive error term), which indicates that the one side error term $u$ dominates the symmetric error $\mathrm{v}$, so the variation of actual output of red pepper production mainly comes from differences in farmer's practice (mismanagement of farm) rather than random variability. Likewise, this verifies the fact that there are measurable inefficiencies in production probably caused by differences in socio-economic characteristic of the households and their management practices. 
Table 1 : Maximum likelihood estimates of Trans log stochastic production function

\begin{tabular}{|c|c|c|c|}
\hline Variable & parameters & Coefficients & Standard error \\
\hline Constant & $\beta 0$ & $8.231431 * * *$ & 7.190745 \\
\hline Ln(labor) & $\beta 1$ & $.1397562 * * *$ & 1.773344 \\
\hline Ln(capital) & $\beta 2$ & $-.9237302 * * *$ & .594075 \\
\hline $\operatorname{Ln}($ farmsize $)$ & $\beta 3$ & $.1726772 * *$ & .3170234 \\
\hline Ln(fertilizer) & $\beta 4$ & $.2427162 *$ & .6150529 \\
\hline (Lnlabor)2 & $\beta 5$ & -.148293 & .1079909 \\
\hline (Lncapital)2 & $\beta 6$ & -.0146952 & .044447 \\
\hline (Lnfarmsize) 2 & $\beta 7$ & -.0034722 & .0096801 \\
\hline (Lnfertilizer)2 & $\beta 8$ & -.0039759 & .0212481 \\
\hline Lnlabor*Lncapital & $\beta 9$ & .2396975 & .0900526 \\
\hline Lnlabor*Lnfarmsize & $\beta 10$ & .0125239 & .0379096 \\
\hline Lnlabor*Lnfertilizer & $\beta 11$ & .0034548 & .0749424 \\
\hline Lncapital*Lnfarmsize & $\beta 12$ & -.0253043 & .0255019 \\
\hline Lncapital*Lnfertilizer & $\beta 13$ & -.025581 & .0473711 \\
\hline Lnfarmsize*Lnfertilizer & $\beta 14$ & -.0092094 & .0181192 \\
\hline \multicolumn{4}{|l|}{ Variance parameters } \\
\hline $\operatorname{lnsig} 2 \mathrm{~V}$ & & -7.435904 & .4338128 \\
\hline $\operatorname{lnsig} 2 u$ & & -5.708459 & .3035471 \\
\hline Lamda $(\delta \mathrm{u} / \delta \mathrm{v})$ & $\Lambda$ & 2.371975 & .0130667 \\
\hline Sigma-v & $\delta \mathrm{v}$ & .0242836 & .0052673 \\
\hline Sigma-u & $\delta \mathrm{u}$ & .0576002 & .0087422 \\
\hline $\operatorname{Gamma}(\kappa 2 / 1+\kappa 2)$ & $\gamma$ & 0.84908542 & .000841 \\
\hline Sigma2 & $\delta 2$ & 0.0039075 & \\
\hline
\end{tabular}

Source: own survey result (2017)

*** shows significant at 1,5 and $10 \%$;* shows significant at 5 and 10 , and $*$ at 10 percent level of significance.

The parameter gamma lies between 0 and 1; with value equal to 0 means that technical inefficiency is not present and a value close or equal to one implying that the frontier model is appropriate estimate of gamma. The maximum likelihood estimates for the parameter gamma $(\gamma)$, furthermore, explains that around $84.90 \%$ of variation in the model is caused by technical inefficiency that is due to inefficiency effects of farmer's specific attributes and the random error accounts for rest $15.10 \%$. This means that the major problem for the deviation of output from the potential level is due to the inefficiency error, ui and not due to the random error, vi beyond control of farmers. The variance $(\delta 2)$ is 0.390 which is different from zero, indicating that a good fit and correctness of specified distribution.

The technical efficiency scores level and distributions were analyzed in this study. Technical efficiency measure takes a value between zero and one: the value 1 implies that farmers are fully productive efficient and correspondingly, the observed output reaches its maximum obtainable level. However, if the value of TE is less than one, there is the short fall of the observed output from maximum feasible output. The result shows that technical efficiency of sample farmers ranged from 0.32 to 0.94 . The distributions of technical efficiency level ranges were 0.62 to 0.80 and 0.81 to 0.91 each category representing $50 \%$ and $46 \%$ respectively. This implies that almost all farmers had the same level of efficiency basically due to that farmers use similar technologies and have the same farming attributes. The average technical efficiency level of producers in the district was $73.66 \%$, which indicates that farmers are only producing on average $73.66 \%$ of their maximum possible output level, given the state of technology; and . about $26.34 \%$ of inefficiency has to be addressed.

Model B: Determinants of Technical efficiency

In the technical inefficiency model, the sign of coefficients of the model is taken in to account (Coelli and Battese, 1996). If the coefficient of the variable in the model is positive, it means that the variable is increasing the level of technical inefficiency of the farmer and whereas, if the sign of the coefficient of the parameter is negative, it shows that the variable under consideration is decreasing the level of technical inefficiency.

Table (3.5) shows that variables such as education level of farmers, age, distance to plot, experience, credit access, extension visit, fertility of soil, proximity to market and off-farm income significantly affected technical inefficiency of producers. Moreover, relative to other variables distance to plot, education, and off farm income more significantly affect the technical efficiency of producers.

The educational level of producers is the variable that negatively and significantly affected technical inefficiency. This indicates that farmers with a formal education are more likely efficient in red pepper production. This could be attributed to more educated farmers may have better access to extension services, financial 
institutions, market information, fast response to new technologies and better manages activities like timely planting and weeding, the appropriate amount of fertilizer , appropriate seed rate and general management of the farm . Ismat et al. (2009) found evidence that schooling improves technical and economic efficiencies. Moreover, access to credit has also a negative and significant effect on technical inefficiency. Actually, it reduces the financial difficulties that farmers face at the beginning of the crop year, thus access to credit enables them to buy farm inputs. This result is also similar to those obtained by Alemayehu (2010).

Table 3.5 Estimated parameters of the inefficiency effects model

Source: the study results (2017)

\begin{tabular}{|l|l|l|l|l|l|}
\hline Inefficiency model & Parameter & Coefficients & Standard error & t-ratio & p-value \\
Constant & $\delta_{0}$ & $0.1854475^{*}$ & 8.25172 & 2.24 & 0.0000 \\
Sex of household & $\delta_{1}$ & 0.00546 & 0.0068 & -0.650 & 0.374 \\
Age of household & $\delta_{2}$ & $0.0046^{* *}$ & 0.00193 & 2.383 & -0.019 \\
Family size & $\delta_{3}$ & 0.00486 & 0.0022 & 1.209 & 0.024 \\
Education & $\delta_{4}$ & $-0.00137^{* *}$ & 0.000354 & -3.87 & 0.029 \\
Experience & $\delta_{5}$ & $0.000801^{*}$ & 0.0003572 & 2.242 & 0.000 \\
Red pepper disease & $\delta_{6}$ & 0.00172 & 0.00335 & 0.51 & 0.607 \\
Off farm income & $\delta_{7}$ & $3.8606^{* *}$ & 1.4742 & -2.61 & 0.043 \\
Credit access & $\delta_{8}$ & $-1.88246^{*}$ & 1.0425 & -4.805 & 0.000 \\
Distance to plot & $\delta_{9}$ & $-0.0387355^{*}$ & 0.01231 & -3.89 & 0.000 \\
Extension visit & $\delta_{10}$ & $-0.00036^{* *}$ & 0.00017 & -2.09 & 0.037 \\
Proximity to mkt & $\delta_{11}$ & $-0.00236^{* *}$ & 0.00196 & -2.20 & 0.032 \\
Fertility of soil & $\delta_{12}$ & -0.0039808 & 0.002549 & -1.58 & 0.118 \\
Slope of land & $\delta_{13}$ & $0.006440^{* *}$ & 0.00321 & 2.006 & 0.060 \\
Variety of seed & $\delta_{14}$ & 0.00425 & 0.00509 & 0.835 & 0.385 \\
\hline
\end{tabular}

$*$, and $* *$ shows significance level at $1 \%, 5 \%$, and $10 \%$ respectively.

The estimated coefficient for the age variable has a positive sign, implying that old farmers are technically inefficient than younger ones. This result can be explained in terms of adoption of modern technologies. Similarly, older farmers are less likely to have contact with extension workers and are equally less inclined to adopt new techniques and modern inputs unlike the younger farmers which make them more skilful in the search for information and the application of new techniques.

The coefficient estimated for the variable indicating contact with extension workers has a negative sign, implying that the technical inefficiency diminishes with the number of visits made to the farm by extension workers. Actually, regular contacts with these workers facilitate the practical use of modern techniques and adoption of agronomic norms of production; the result contradicts with Alemayehu (2010) .

Proximity to the market was another variable that has negative and significant effect on inefficiency of farmers, reflecting that those farmers who are close to market centers are technically more efficient than farmers away from market center. This implies that farmers near market center could get vital market information that could ease resource allocation in red pepper crop production and thereby enhance technical efficiency. This finding is in line with Alemu et al (2008). Similarly, distance to plot is also another variable affecting technical inefficiency of farmers. It is statistically significant. The result shows that there is negative relation with inefficiency of farmers. This means that farmers give more attention, concentration and strong supervision to farm/plot that far away from their home and so would be efficient.

The off- farm income is significant variable that positively affects technical inefficiency of producers in the study area; indicating that red pepper producers who earn more off- farm income are tending to be more inefficient. This is may be due to the farmers who have more off farm income may not give due emphasis to their farm and might use this income as an alternative source of livelihood. This result contrasts with the result reported by Getu (2005). In addition, the estimated coefficient of the variable representing the farmers' Experience indicates that inefficiency increases with the number of years spent in red pepper production.

\section{CONCLUSION}

This study result explained the existence of technical inefficiencies in red pepper production. The significant value of gamma, $\gamma=84.90 \%$ reveals the fact that a high level of technical inefficiency exists among the sample farmers. The wide variation in technical efficiency reveals that most of the farmers use resources inefficiently in the production process and there still exists opportunities for increasing their crop production by improving technical efficiency.

Furthermore, the study result also showed that labor, capital and fertilizer were variables that positively affect red pepper production. Therefore, by increasing (improving) these inputs at optimum level, the level of technical efficiency of red pepper producers will increase.

The red pepper producing farmers use similar technologies with the same farming attributes in the study area 
and the difference in these could not cause efficiency variation; thus, efficiency variation among the farmers is due to the difference in amounts of inputs they have used. However, there is a scope for improving efficiency by using the present technology and overcome output loss due to the technical inefficiency.

The benefits of introduction of modern technologies cannot be realized in the presence of higher technical inefficiency. Therefore the efficiency can be improved if principal factors that determine efficiency are identified. Thus, variables such education level of farmers, age, distance to plot, experience, credit access, extension visit, fertility of soil, proximity to market and off-farm income significantly affect the technical efficiency of red pepper producers.

\section{RECOMMENDATIONS}

In the study it was evidenced that there was inefficiency in red pepper production and factors affecting the efficiency were identified. Based on the findings; therefore, the following specific recommendations has been forwarded

- Government should take necessary policy measures to lower the price of inputs as it increase the net benefit of red pepper producers.

- Adequate training on recommended fertilizer dose, use of good seed, intercultural operations, etc., should be provided to the farmers which will enhance the technical efficiency by improving knowledge of the farmers.

- Government should encourage financial institutions like Omo-microfinance to provide financial support which in turn help the farmers for purchasing inputs.

- Development agents should give continuous support to farmers and local government also ought to follow up their accomplishments.

- The study result revealed that environmental factors such as soil fertility affect technical inefficiency of the producers and thus government has to concern about soil fertility maintenance program and corporate with NGOs those concern this issue.

- Since distance to plot and proximity to market are important factors that affect technical efficiency, the road net work in the rural areas; development of telecommunication facilities, rural market centers (institutions) should have to be advocated for farmers.

\section{References}

Aigner, D.J., Lovell, C.A.K. and Schmidt, P.(1977). "Formulation and Estimation of Stochastic Frontier Production Function Models", Journal of Econometrics,pp. 21-37.

Alemnew Abay 2010; Market Chain Analysis of Red Pepper in Case of Bure Woreda, West Gojjam Zone, Amhara National Regional State; MSc. Thesis, college of Agriculture, Haramaya University; Ethiopia pp. 108.

Alemu, Nuppenuua and Bolland (2009); Technical effeciency of farming systems across agro Ecological zones in Ethiopia: an application of stochastic frontier approach.Agricultural Journal, 4, pp. 112-125.

Almaz Giziew, Workneh Negatu, Edilegnaw, Wale and Gezahegn Ayele (2014). Constraints of Vegetables value chain in Ethiopia. International Journal of Advanced Research in Management and Social Sciences, 3(12): pp.44-71

Coelli, T.J. and Battese, G.E.(1996). Identification of Factors which Influence the Technical Inefficiency of Indian Farmers: The Australian Journal of Agricultural Economics. 40(2): 103-128.

Coelli, T.J., (1995). Recent Development in Frontier Modelling and Efficiency Measurement. Australian Journal of Agricultural Economics, pp. 219-245.

CSA(2016). Agricultural Statistics 2015/2016; Addis Ababa, pp.121.

Demeke Mekuria, (2008). Impact of Small Scale Irrigation Schemes on Poverty Reduction: The Case of Bahir Dar Zuria District in West Gojjam Administrative zone. M.Sc. Thesis Presented to the School of Graduate Studies of Haramaya University.

Essa Chanie (2011). Resource Use Efficiency of Smallholder Crop Production in the Central Highlands of Ethiopia; MSc. Thesis Presented to Department of Agricultural Economics and Business Management, Egerton University, Kenya.

Fikadu Gelaw, (2004). Analysis of Technical Efficiency of Wheat Production in Machakel District, Ethiopia. M.Sc. Thesis presented to the School of Graduate Studies of Alemaya University.

Getu. (2005). Technical efficiency of small holder cereal production in Ethiopia. A Stochastic frontier analysis using panel data from selected villages: Economics Department, Addis Ababa University.

Haileselassie Amare, (2005). Analysis of Technical Efficiency in Sorghum Production: The Case of Smallholder Farmers in Raya-Azebo District, Southern Tigray, Ethiopia. M.Sc. Thesis Presented to the School of Graduate Studies of Alemaya University.

Herror.I., S.Pascoe. (2002). Estimation of Technical Efficienvy: A Review of some of the stochastic frontier and DEA software, CHEER Virtual Edition, 15(1). 
Ismat, A., J. Begum, M. Buysse, A. Jahangir and G. Van Huylenbroeck, (2009). An Application of Data Envelopment Analysis to Evaluate Economic Efficiency of Poultry Farms in Bangladesh, Contributed Paper Prepared for Presentation at the International Association of Agricultural Economists Conference, Beijing, China.

Jema. (2008). Economic efficiency and marketing performance of vegetable production in the Eastern and Central parts of Ethiopia. Appsala: Faculty of Natural Resource and Agricultural economics Swedish University

Kindie Teshome, (2005). Technical Efficiency of Maize Production: A Case of Smallholder Farmers in Assosa District. M.Sc. Thesis Presented to the School of Graduate Studies of Alemaya University.

Kumbhakar, S.C. and Lovell, C.A.K (2005). Stochastic Frontier Analysis. New York. Cambridge University Press.

Mbanasor, J. and K.C. Kalu, (2008). Economic Efficiency of Commercial Vegetable Production System in Akwa Ibom State, Nigeria. Journal of Tropical and Subtropical Agroecosystems, 8(3): pp. 313-318.

Mekdes Abera, (2011). Analysis of Technical efficiency of irrigated Lentil (Lens Culinaris Medikus) Production: the case of Gimbichu District, Ethiopia. M.Sc. Thesis presented to the School of Graduate Studies of Haramaya University.

Mohammed B., Abdulsalam Z. and Ahmed B., (2015). Profitability in Chilli Pepper Production in Kaduna State, Nigeria. British Journal of Applied Science and Technology, pp. 1-9.

Nyagaka1 D.O., G. A. Obare and W. Nguyo, (2009). Economic Efficiency of Smallholder Irish Potato Producers in Kenya: A Case of Nyandarua North District, Beijing, China.

Shih-wen Lin, Yu-yu Chou, Hsueh-ching Shieh, Andreas W., Ebert, Sanjeet Kumar, Ravza Mavlyanova, Albert Rouamba, Abdou Tenkouano,Victor Afari-Sefa and Paul A. Gniffke (2013). Pepper (Capsicum spp.) Germplasm Dissemination by AVRDC.The World Vegetable Center: an Overview and Introspection. Chronica Horticulture, 53 (3):21-27

Smith, D. (2000) The Spatial Dimension of Access to the Rural Non- Farm Economy. Draft paper. Chatham, UK: Natural Resources Institute.

Solomon Bizuayehu, (2012). Economic Efficiency of Wheat Seed Production: The Case of Small holders in Womberma Woreda of West Gojjam Zone. M.Sc. Thesis Presented to the School of Graduate Studies of Haramaya University.

Storck, H., Bezabih Emana, Berhanu, Adinew. Borowiesck and Shimelis Weldeha wariat, 1991 Farming System and Farm Management Practices of Smallholder in the Hararghe Highlands; Farming Systems and Resource Economics in the Tropics, 11 (1)

Tewodros. (2001). Farm household technical efficiency: A stochastic frontier analysis. A study of rice producers in Mardi Water land in Western development region of Nepal, Department of economics and social science.

Tsegaye Yilma. (2004). Technical efficiency of maize production in Southeastern Ethiopia: A case study of Jimma Zone.

Weir and Knight (2004). Education Externalities in rural Ethiopia. Evidence from average And productions function. New York: working paper CSAEWPS, University of Oxford.

Yamane, T., (1967). Statistics: An Introductory Analysis, (2nd ed.), New York, Harper and Row. 